\title{
Can we reverse the process of deterioration in a run down prairie grass pasture?
}

\author{
M.B. Dodd, A.C.P Chu and P.N.P. Matthews
}

Agronomy Department, Massey University

Palmerston North

\begin{abstract}
An experiment was designed to determine whether aerating soil with a seed drill coulter, or improving soil fertility through nitrogen application, could reverse the deterioration of a 'Grasslands Matua' prairie grass pasture. A simple model outlining the changes in yield components characteristic of pasture deterioration is proposed, against which the effects of the treatments have been compared. The aeration treatment accelerated deterioration, probably because the technique caused plant damage and/or soil compaction. However, autumn nitrogen application was successful in reversing the early stages of pasture deterioration by improving plant size through increased tiller size.
\end{abstract}

Keywords Matua prairie grass, Bromus 'willdenowii Kunth, soil aeration, nitrogen, model, yield components

\section{INTRODUCTION}

Trial work (Wilson 1977; Hay \& Ryan 1983; Fraser 1985) showed that 'Grasslands Matua' prairie grass (Bromus willdenowii Kunth) was palatable with good growth potential in winter/ spring and summer/autumn, However, rapid deterioration of Matua pastures has been noted on poorly drained soils (Ridler 1986) or on soils of low pH and fertility (Clark 1985), and where management has been inappropriate (Matthews 1986; Black \& Chu 1989). Insect damage has also contributed to sward decline in some regions (Thorn \& Prestidge 1988).

Matua pastures often deteriorate more rapidly on heavy, fine textured soils, particularly where these are prone to winter waterlogging (Sellars 1988). A feature of such soils is poor aeration (Eccles 1988) which implicates it as a factor in the deterioration of Matua pastures. The most poorly aerated soils are those artificially compacted by stock or machinery (Payne 1988), and overseas work has shown that prairie grass yield and persistence are both reduced on compacted soils (Cavallero \& Cereti 1986). Poor soil aeration also retards mineralisation of essential nutrients such as nitrogen (Harris 1988). Dry matter production of Matua has been shown to respond well to nitrogen fertiliser (Rys et al. 1978).
This paper gives results from a short-term experiment examining the role of improved soil aeration and nitrogen fertiliser application on the rejuvenation of a deteriorated prairie grass pasture.

\section{METHODS AND MATERIALS}

\section{Trial site}

The experiment was conducted in a single paddock on No. 4 Dairy Farm, Massey Universtiy, over 12 weeks from May to August 1988. The soil type is Tokomaru silt loam, a typically heavy yellow-grey earth with winter wet and summer dry limitations, though the paddock has been mole and tile drained. Matua prairie grass was sown on the site in spring 1985 , but at the beginning of the trial was considered 'rundown' because of poor regrowth after grazing. The pasture received annually $300 \mathrm{~kg} /$ ha Hyphos + S + K (O-10-10-15). Nitrogen $(\mathrm{N})$ was last applied in March 1987.

\section{Experimental treatments and design}

The technique of soil aeration applied was a single pass over the length of the plots with a seed drill incorporating inverted ' $\mathrm{T}$ ' coulters (Massey University Agricultural Machinery Research Centre 'Bioblade'). This achieved a shallow soil shattering effect intended to improve soil porosity. Nitrogen fertiliser was spread by hand as urea.

A factorial design was used with 3 levels of the aeration factor and 2 levels of the $\mathrm{N}$ factor, partially randomised within 4 block replications. The 3 levels of soil aeration corresponded to no drilling $\left(\mathrm{A}_{0}\right)$, shallow drilling (2-3 cm depth, A,) and deep drilling (5-6 $\mathrm{cm}$ depth, $\left.\mathrm{A}_{2}\right)$. The two levels of $\mathrm{N}$ were $0 \mathrm{~kg}$ $\mathrm{N} / \mathrm{ha}$ and $50 \mathrm{~kg} \mathrm{~N} / \mathrm{ha}$. All treatments were applied to $30 \mathrm{~m}$ x $20 \mathrm{~m}$ plots on 17 May, 2 weeks after a grazing by dairy heifers.

\section{Measurements}

Herbage mass was measured at weeks 1,6 and 12 with a pasture probe calibrated in the paddock. Four $0.25 \mathrm{~m}^{2}$ quadrats in each plot were randomly fixed at week 1 and the plants tagged and recorded in plant size categories. These categories were based on a visual plant vigour scoring system according to tiller number and size. The scale used was 1 (small seedling) to 10 (large plant). Plants in the fixed quadrants were scored again at the end of the trial. Two randomly placed $0.25 \mathrm{~m}^{2}$ quadrants in each plot were cut to ground level at week 12 and the 
tillers grouped into large, medium and small according to basal width ( $>5 \mathrm{~mm}, 2-5 \mathrm{~mm},<2$ $\mathrm{mm}$ respectively). The tillers in each group were then counted, dried and weighed.

\section{RESULTS}

The aeration treatment significantly $(\mathrm{P}<0.01)$ decreased herbage accumulation over the first 6 weeks (Table la). Both levels decreased the proportion of large plants in the sward, and the deep level also increased the proportion of small plants (Figure la). Figure 2a shows conflicting results for the effects of the two levels of aeration. The shallow level appeared to increase total tiller numbers, yet no change in the proportion of each size group was evident. The deep level appeared to decrease total tiller numbers with a significant $(\mathrm{P}<0.01)$ decrease in the proportion of large tillers. Both levels significantly decreased mean tiller weights of the size groups (Table $2 a$ ).

Table la Herbage mass grown (kg DM/ha)

- Aeration treatment.

\begin{tabular}{|c|c|c|c|c|}
\hline (weeks) & $A_{0}$ & $\mathrm{~A}_{1}$ & $\mathrm{~A}_{2}$ & SED \\
\hline 1 & 720 & 340 & 300 & 120 \\
\hline 6 & 2130 & 1350 & 1250 & 140 \\
\hline 12 & 1980 & 2000 & 1640 & 190 \\
\hline
\end{tabular}

Table lb Herbage mass grown ( $\mathrm{kg}$ DM/ha)

- Nitrogen treatment.

\begin{tabular}{|c|c|c|c|}
\hline Period (weeks) & $N_{0}$ & $\mathrm{~N}_{1}$ & SED \\
\hline 1 & 410 & 490 & 12 \\
\hline 6 & 1400 & 1760 & 75 \\
\hline 12 & 1800 & 1940 & 87 \\
\hline
\end{tabular}

Nitrogen application significantly $(\mathrm{P}<0.01)$ improved net herbage accumulation after the first 6 weeks (Table $1 \mathrm{~b}$ ) and increased the proportion of large plants in the sward (Figure lb), a reversal of the trends noted above for aeration. In the tiller population survey, although tiller weights in each size group did not significantly differ (Table 2b), the $\mathrm{N}$ treatment significantly increased the proportion of large tillers and decreased (non-significant) the proportion of small tillers (Figure $2 b$ ).

Table $\mathbf{2 a}$ Average weight of tillers from final harvest (g DM/100 tillers) Aeration treatment.

\begin{tabular}{lrrrr}
\hline Size grouping & $\mathrm{A}_{0}$ & $\mathrm{~A}_{1}$ & $\mathrm{~A}_{2}$ & $\mathrm{SED}$ \\
\hline Small & 10.4 & 7.1 & $\mathbf{5 . 6}$ & $1 . \mathbf{5}$ \\
Medium & $\mathbf{2 8 . 2}$ & $\mathbf{1 9 . 5}$ & 19.4 & 1.4 \\
Large & $\mathbf{7 3 . 0}$ & $\mathbf{4 8 . 1}$ & $\mathbf{5 5 . 3}$ & $\mathbf{9 . 1}$ \\
\hline
\end{tabular}

Table 2b Average weight of tillers from final harvest (g DM/100 tillers) Nitrogen treatment.

\begin{tabular}{lccr}
\hline Size grouping & $\mathrm{N}_{0}$ & $\mathrm{~N}_{1}$ & $\mathrm{SED}$ \\
\hline Small & 1.5 & 7.8 & 0.6 \\
Medium & 22.5 & 22.3 & 1.9 \\
Large & 58.6 & 59.1 & 8.8 \\
\hline
\end{tabular}

The interaction between the shallow aeration and the $\mathrm{N}$ treatment was significant $(\mathrm{P}<0.05)$ and negative for the herbage accumulation data at weeks 1 and 6. Specifically, a N response occurred under the control and deep drilling treatments but not under the shallow drilling treatment.

\section{DISCUSSION}

Pasture deterioration has in the past been described in terms of changes in botanical composition (Morrison 1979). Dodd (1988) suggested an alternative approach which concentrates on changes in the yield components (plants/m*, tillers/plant, weight/tiller) of the species under consideration. Specifically, the process of pasture deterioration is considered to, begin with a decrease in plant size (initially tiller size then tiller numbers/plant) followed by a decrease in plant population.
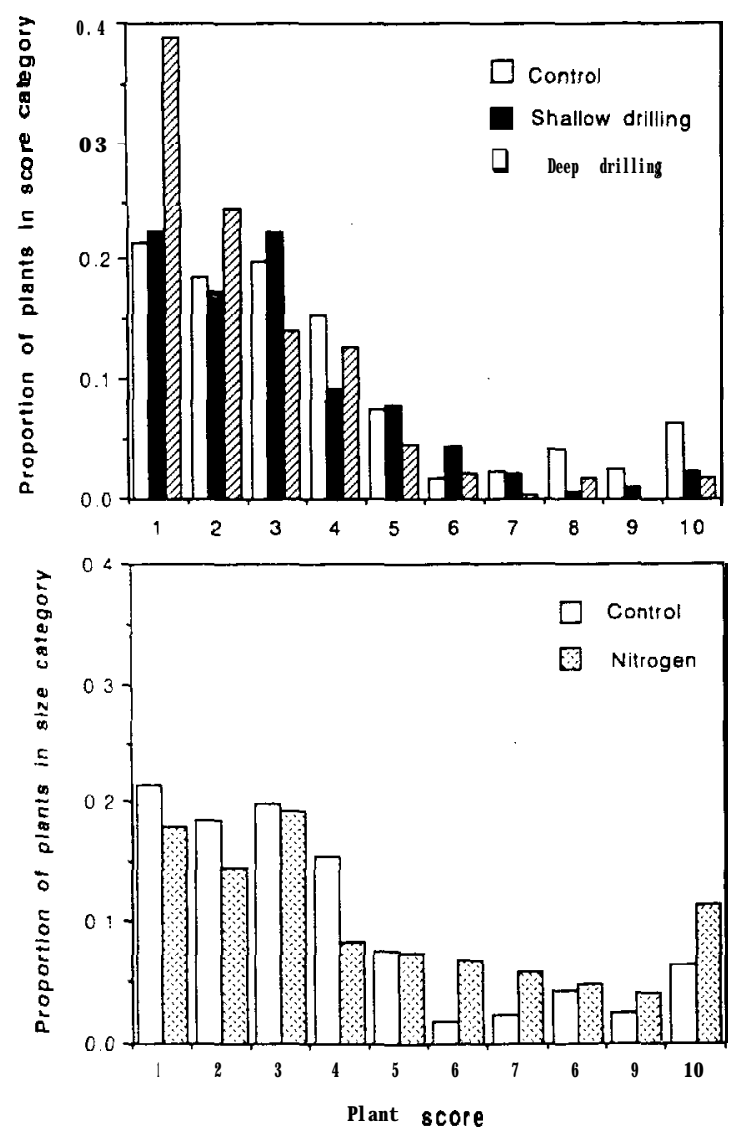

Figure 1 (a-upper) Frequency distribution of plant size at 12 weeks (aeration treatment); (b-lower). Frequency distribution of plant size at 12 weeks (nitrogen treatment).

Often a deteriorating pasture will not be recognised as such until plant population begins to decrease, but at this stage it will be too late to 
remedy without resowing or regeneration by seed set. By concentrating on monitoring tiller or plant size, an 'early warning' of deterioration can be picked up, and it will be possible to act to reverse deterioration sooner and perhaps more cheaply.

Hence, in this trial, the sward was specifically chosen as representing a deteriorating pasture, but one not yet too diminished in plant numbers. Measure-ments of tiller size and plant size were considered appropriate for monitoring changes in the state of deterioration of the sward.
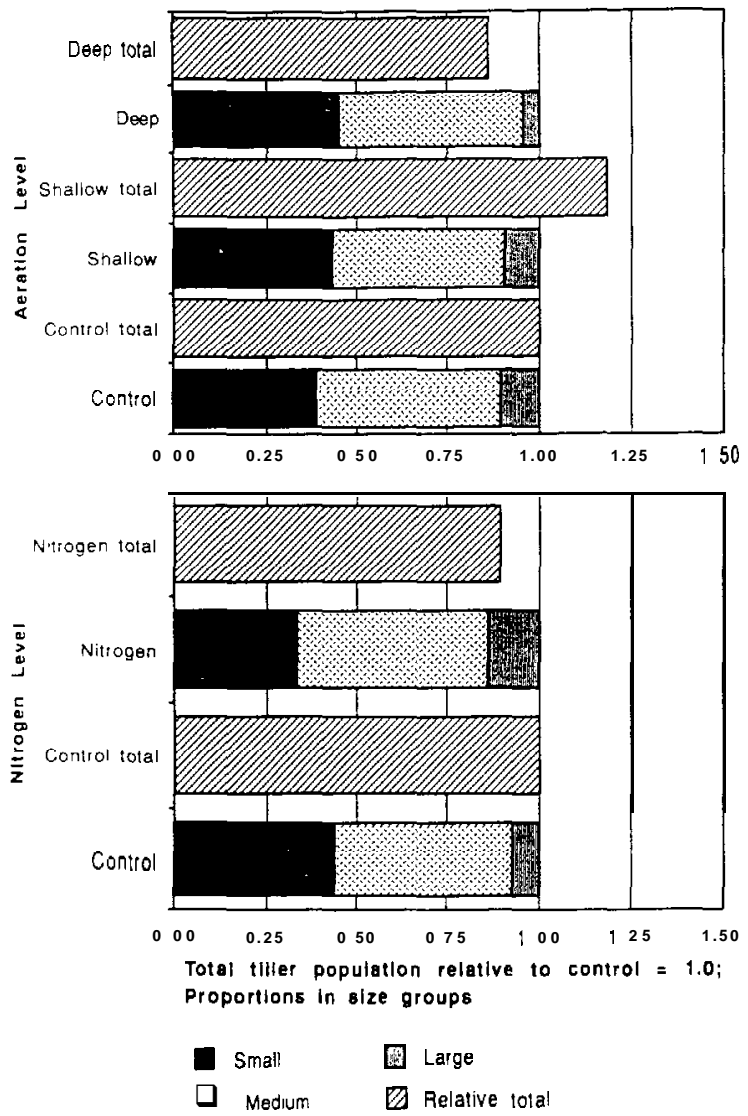

Figure 2 (a-upper) Tiller population analysis at 12 weeks (aeration treatment); (b-lower) Tiller population analysis at 12 weeks (nitrogen treatment).

The technique of soil aeration applied apparently advanced pasture deterioration, given that tiller weights and plant size were diminished. This was due to adverse side effects of the treatment. It was observed that the wheels of the tractor pulling the drill compressed the soil and also caused some uprooting of plants. Soil compaction was therefore possible. In addition the negative interaction between the shallow aeration and $\mathrm{N}$ treatments suggest that roots may have been damaged by the horizontal base of the drill coulter, thereby preventing $\mathrm{N}$ uptake.
Whatever the cause(s), the drilling treatment accelerated deterioration according to the model outlined. Therefore the results do not support the use of this shallow soil shattering technique as a means of improving aeration, and the role of improved soil aeration in reversing deterioration has not been confirmed.

Nitrogen application improved sward regrowth, and, according to the suggested model, pasture deterioration in its early stages can be said to have been reversed. Other measurements of individual plants (unpubl.) showed that $\mathrm{N}$ significantly increased plant size. This, combined with indications of a possible decrease in tiller numbers, and a definite increase in the 'large tiller' population (Figure 2b), points to improved tiller size being the component responsible for improved regrowth.

The good dry matter response of Matua to the autumn $\mathrm{N}$ application (an average of $11.5 \pm 2.9 \mathrm{~kg}$ $\mathrm{DM} / \mathrm{kg} \mathrm{N}$ ) implies that Matua will respond to strategic N application. Cosgrove \& Brougham (1988) claim that Matua is more responsive (in DM production) to $\mathrm{N}$ in winter than ryegrass, though there is some evidence to the contrary (Rys et al. 1977). In this location at least, lack of $\mathrm{N}$ supply appears to be limiting the winter production potentail of Matua. This may be a result of poor mineralisation under winter soil conditions (i.e. a low temperature, high leaching, anaerobic soil environment) or the inability of companion legumes to supply $\mathrm{N}$ to the grass during this period.

\section{CONCLUSIONS}

The technique of soil aeration failed to reverse the process of pasture deterioration, because of uncertain adverse side effects.

The winter application of $\mathrm{N}$ fertiliser is effective in reversing deterioration, at least in its early stages, by improving plant vigour.

Acknowledgements The authors would like to thank Gerard Lynch and Grant Rowan of No. 4 Dairy Farm, Massey University; Terry Lynch and his staff for technical assistance; and members of the staff and postgraduate students in the Agronomy Department, Massey University for helpful discussion.

\section{REFERENCES}

Black, C.K.; Chu, A.C.P. 1989 Searching for an alternative way to manage prairie grass. Proceedings of the NZ Grassland Association 50:2 19-223.

Cavallero, A.; Cereti, C.F. 1986. The effects of soil compaction by harvesting machinery on some multispecies rotational pastures. Herbage Abstracts 56(9):3663.

Clark, P. 1985. Matua prairie grass establishment. Proceedings of the NZ Grassland Association 46:147-149. 
Cosgrove, G.P.; Brougham, R.W. 1988. Pasture strategies for dairv beef production. Proceedings gf the $N Z$ Grassland Association 49:57-62.

Dodd, M.B. 1988. Soil aeration and foliar nitrogen application as a means of renovating a rundown prairie grass sward. BAgrSci (Hons) Thesis, Agronomy Department, Massey University.

Eccles, W.J. 1988. A study on the relationship between soil oxygen concentration, soil moisture, and growth of prairie grass under different soil types. BAgrSci (Hons) Thesis, Agronomy Department, Massey University.

Fraser, T.J. 1985. Role of Matua prairie grass in an all grass system for prune lamb production. Proceedings of the NZ G rassland Association 46:157-167.

Harris, P.J. 1988. Microbial transformations of nitrogen. pp. 378-411. In Wild A. (Ed.) Russell's Soil Conditions and Plant Growth. 1 lth edition. Longman Scientific and Technical New York.

Hay, R.J.M.; Ryan, D.L. 1983. An evaluation of Pawera red clover with perennial grasses in a summer dry environment. Proceedings of the NZ Grassland Association 44:91-97.

Matthews, P.N.P. 1986. Matua prairie grass: Changes in anproach. Publication No. 3, Massey Farm Series, Matua Prairie Grass: pp 12-14.
Morrison, J. 1979. Botanical change in agricultural grassland in Britain. pp S-10. In Charles A.H., Haggar R.J. (Eds.) Changes in Sward Composition and Productivity. Occasional Symposium No. 10 British Grassland Society.

Payne, D. 1988. Soil structure, tilth, and mechanical behaviour. pp 378-411. In Wild A. (Ed.) Russell's Soil Conditions and Plant Growth. 1 lth edition. Longman Scientific and Technical, New York.

Ridler, B.J. 1986. Experience with Matua at No. 4 Dairy Farm. Publication No. 3, Massey Farms Series, 'Matua Prairie Grass' pp 15-25.

Rys, G.J.; Ritchie, I.M.; Smith, R.G.; Thomson, N.A.; Crouchley, G.: Steifel, N. 1978. The performance of Grasslands Matua prairie grass. Proceedings of the NZ Grassland Association 39: 148- 151 .

Sellars, M.D. 1988. Manawatu dairy farmers experience with Matua prairie grass. Proceedings of the NZ Grassland Association 49: 185-1 86 .

Thorn, E.R.; Prestidge, R.A. 1988. High performance pastures for high quality cows? Proceedings Ruakura Farmers Conference: 13-17.

Wilson, G.F. 1977. 'Grasslands Matua' prairie grass. New Zealand Agricultural Science 1I(1):47-48. 